5 Балабаев Е. Оқытуу мен білім беру проиесінің жүйесі, құрлымы мен фунииялары. group-global.org/../3911okytu-men-bilim-beru-procesinin-zhuye..

6 Тұрабаева Л.Қ. Мәтінмен жұмыс жасау арқылы мектеп оқушыларының тілін дамыту. Хабариы. Абай атындавы ҚазҰПУ. №2(52), 2015.-230-233бб.

References:

1. Qoianbaev J.B., Pedagogika: Universitetter studentterıne arnalğan oqu qūraly. - Almaty, $2004-420$ b.

2. Pedagogicheskaia ensiklopedia. T.2. - Moskva, 1965. - $272 \mathrm{~s}$.

3. Harlamov İ.F. Pedagogika: Ucheb. posob. - Moskva: Gardariki, 2003.-519 s.

4. Nabuova R. Daryndy balalardyñ äleuetın damytu faktorlary». Qazırgı bastauyş bılım berude oquşylardyñ funksionaldyq sauattylyğyn damytudyñ özektı mäselelerı» atty halyqaralyq ğylymi-praktikalyq konferensia jinağy. Qazmemqyzpu. 2016j.-213-216 bb.

5. Balabaev E. Oqytu men bilım beru prosesınıñ jüiesı, qūrlymy men funsialary. group-global.org/.../3911-okytumen-bilim-beru-procesinin-zhuye..

6. Türabaeva L.Q. Mätınmen jūmys jasau arqyly mektep oquşylarynyñ tılın damytu. Habarşy. Abai atyndağy QazŪPU. №2(52), 2015.-230-233bb.

МРНТИ 16.01.07 https://doi.org/10.51889/2020-4.1728-7804.86

\author{
Ли Дуо ${ }^{1}$ \\ ${ }^{1}$ Казахский национальный педагогический университет имени Абая, \\ Алматы, Казахстан
ВИДЕОУРОКИ КАК ОДИН ИЗ ЭФФЕКТИВНЫХ МЕТОДОВ В ОБУЧЕНИИ РКИ КИТАЙСКИМ СТУДЕНТАМ

\begin{abstract}
Аннотация
Русский язык - один из самых богатых языков современности. В настоящее время на русском языке говорит более 200 миллионов человек. Он входит также в число десяти рабочих языков ООН. Русский язык является одним из наиболее сложных для изучения иностранными студентами, что обуславливает необходимость более качественного подхода к образовательному процессу. В статье рассматривается изучение проблемы повышения эффективности обучения китайских студентов русскому языку как иностранному. Предлагается решение проблемы во вспомогательном применении видеоуроков. Проводится анализ нескольких существующих видеоуроков, доступных онлайн. Рассматриваются сравнительным методом сложные моменты, которые могут возникнуть у китайских студентов, обучающихся русскому языку. Подтверждается то, что создание нового видеоурока и лингвометодические основы его внедрения в образовательный процесс имеют новизну и актуальность.
\end{abstract}

Ключевые слова: русский язык как иностранный, видеоуроки, методика, китайские студенты, онлайн

$$
\text { Li Duol }
$$

${ }^{I}$ Abay Kazakh national pedagogical University, Almaty, Kazakhstan

\title{
VIDEO LESSONS AS ONE OF AN EFFECTIVE METHODS IN TEACHING RCL TO CHINESE STUDENTS
}

\section{Abstract}

The Russian language is one of the richest languages of our time. Currently, more than 200 million people speak Russian. It is also one of the ten working languages of the United Nations. The Russian language is one of the most difficult for foreign students to learn, which necessitates a better approach to the educational process. The article examines the study of the problem of increasing the effectiveness of teaching Chinese students Russian as a foreign language. A solution to the problem in the auxiliary application of video tutorials is proposed. An analysis of several existing video tutorials available online is being carried out. The article deals with the comparative method of difficult moments that may arise for Chinese students studying Russian. It is confirmed that the creation of a new video lesson and the linguo-methodological foundations of its implementation in the educational process are new and relevant.

Keywords: russian as a foreign language, video lessons, methods, chinese students, online

$$
\text { Ли Дуо }{ }^{1}
$$

\footnotetext{
${ }^{1}$ Абай атындавы Қазақ ұлттық педагогикальљқ университеті,
} 


\section{ВИДЕО САБАҚТАРДЫ ҚЫТАЙ СТУДЕНТТЕРІНЕ ОҚЫТУДЫН ТИІМДІ ӘДІСТЕРІНІҢ БІРІ}

\section{Аңдатпа}

Орыс тілі - біздің заманымыздың ең бай тілдерінің бірі. Қазіргі уақытта 200 миллионнан астам адам орыс тілінде сөйлейді. Бұл сондай-ақ Біріккен Ұлттар Ұйымының он жұмыс тілінің бірі. Шетелдік студенттер үшін орыс тілі оқытудың ең қиын тілдерінің бірі болып табылады, бұл оқу үдерісіне жақсырақ қарауды қажет етеді. Мақалада қытай студенттеріне орыс тілін шет тілі ретінде оқытудың тиімділігін арттыру мәселесін зерттеу қарастырылған. Видеосабақтар көмекші қосымшасындағы мәселені шешу ұсынылады. Интернетте қол жетімді бірнеше бейне сабақтарына талдау жасалуда. Мақалада орыс тілін оқып жатқан қытай студенттері үшін туындауы мүмкін қиын сәттердің салыстырмалы әдісі қарастырылған. Жаңа бейне сабақты құру және оны білім беру процесінде жүзеге асырудың лингво-әдістемелік негіздері жаңа және өзекті екендігі дәлелденді.

Түйін сөздер:шет тілі ретінде орыс тілі, бейне сабақтар, әдістер, қытай студенттері, онлайн

Введение.Русский язык является одним из наиболее сложных для изучения иностранными студентами, что обуславливает необходимость более качественного подхода к образовательному процессу. В целях успешного преподавания языка необходимо освоить различные методики, учесть национально-культурные, индивидуальнопсихологические и личностные особенности учащихся.

Русский язык в Китае преподавался более 300 лет. Первая школа открыта в 1708 году при династии Цин для китайских дипломатов. Первый учебник русского языка был издан в 1798 г. В составе первого в Китае училища иностранных языков - Тонвэнь (1862 г.) - вошла школа русского языка. Начиная с 1920-х гг. в Китае организуются курсы и школы, институт при Министерстве иностранных дел и Шанхайский университет с отделением русского языка. В преподавании применялась грамматико-переводная методика. С образованием в 1949 г. Китайской Народной Республики русский язык получил статус обязательного и единственного иностранного языка для изучения в школах.

Во время «культурной революции» (1966-1976), произошло разрушение системы образования КНР, в том числе и преподавания русского языка. С принятием в 1978 нового политического курса - «реформ и открытости» - в школах вновь вводится изучение русского языка. По статистическим данным, к 2010 г. число учащихся, изучающих русский язык в средних школах КНР, составило 83 тыс. человек. По мнению экспертов, несмотря на явные достижения, обучение русскому языку в КНР осложнено рядом проблем. Значительная часть учебно-методических материалов содержит устаревшие понятия, реалии, названия.

Методы. Рассмотрим китайские традиции в лингвометодике и психологии обучения и проблемы, относящиеся к изучению русского языка как иностранного.

Главным методом обучения в китайских университетах является грамматико-переводной. Учащиеся переводят тексты и пытаются таким образом понять язык. Такой метод усложняет понимание языка[1,75].

Студенты в большей степени слушают преподавателя, чем вступают с ним в дискуссию или возражают. Из-за этого в дальнейшем происходят проблемы при устном общении. Китайский учащийся понимает речь, но ответить затрудняется.

Учащиеся предпочитают коллективную работу, мало задают вопросы и отвечают. Это обусловлено историческими традициями и философией Китая. Статусные взаимоотношения между учителем и учеником, где преподаватель имеет безусловный авторитет, также накладывают определенные ограничения в процессе освоения языка. Учащийся фактически не имеет права на ошибку.

Письменность у китайской цивилизации являлась главным инструментом развития, поэтому в процессе изучения языка применяется в основном доска и мел. Имеется недостаток прочих наглядных образовательных средств.

Традиционные методы обучения используют заучивание слов без учета интонации, важной в русском языке, что создает трудности у китайских студентов.

Основным учебным пособием в КНР является учебник «Русский язык - Восток», составленный в Пекинском университете иностранных языков. Лексика учебника из-за развития общества уже устарела, необходимо применять иные учебные материалы.

Для знания языка недостаточно грамматики и словарного запаса, требуется также контекст, который состоит из культурных, социологических и страноведческих сведений тех регионов, где активно применяется русский язык.

Проверка результатов изучения языка в Китае проходит в форме жесткого контроля: письменного тестирования лексики и грамматики. Достаточного внимания устной речи и активной речевой практике не уделяется.

В широком масштабе имеется недостаток методологической базы КНР в условиях слабой интеграции с международным научным сообществом.

Процесс преподавания русского языка как иностранного для китайских студентов имеет определенные сложности, происходящие от разницы двух языков. Рассмотрим их подробнее. 
При изучении русского языка наблюдаются интерферентные ошибки, возникающие в результате того, что китайский и русский язык относятся к разным типам: аморфному и флективному соответственно.

В морфологическом аспекте можно отметить существенные сходства и различия в явлениях, связанных с местоимениями в языках [2,27-44]. Например, в устной и письменной речи на русском языке у китайских студентов часто встречаются ошибки, связанные с отсутствием разделения личных и притяжательных местоимений, указательных местоимений, таких как «этот», «тот». Местоимение 自己(«сам», «сама») в китайском языке относится к личным и употребляется совместно с другими местоимениями, а в русском относится к возвратным.

Знание специфики использования местоимений, помимо их лексических и грамматических свойств, поможет китайским студентам избегать ошибок в речи на русском языке.

Взаимодействие лексических систем двух языков также создает некоторые трудности, мало точек соприкосновения. В русском и китайском языках много лексики, которая не имеет соответствий, выражаемых одним словом [3, 245]. Также зачастую не совпадает структура многозначных слов и их семантический объем. В случае однозначных слов привлечь внимание обучающихся студентов можно, представив их предметно-наглядно. Для многозначных слов требуется более глубокий подбор наглядного материала, который будет показывать контекст употребления слова в зависимости от его значения.

Синонимы русского языка также представляют сложности для китайских студентов, потому как различия в оттенках значений понимаются в процессе практики языка и формирования восприятия мира посредством языка. Сложносокращенные и сложные слова студентами не воспринимаются, как состоящие из частей знакомых слов.

Для решения проблемы наглядными методами необходимо уделить большое внимание подбору материала, который бы демонстрировал разнообразие контекстных вариантов употребления слов, их синонимов, сложных слов. Помимо наглядности необходимо использование различных упражнений, облегчающих усвоение.

Еще один проблемный участок - это наличие в Китае нескольких крупных диалектов. Из-за больших фонетических различий между ними, у студентов, изучающих русский язык, возникают различные акцентные и орфоэпические трудности в речи. Например, у учащихся-носителей шанхайского диалекта, в отличие от путунхуа(普 通话), возникает смешение свистящих и шипящих согласных, звуков /ж/ и /л/ [4, 101-103]. С другой стороны, у учащихся-носителей путунхуа наблюдаются трудности в различении глухих и звонких согласных русского языка, с чем обычно не возникает проблем у шанхайских студентов, в диалекте которых есть звонкие согласные.

Материалы. Для решения проблемы необходимо учитывать целевую аудиторию, родной диалект учащихся и согласно этому подготавливать различные материалы.

Рассмотрим особенности некоторых существующих видеоуроков обучения русскому языку, предназначенные для китайских студентов.

1. Быстрый старт русского с нуля [5].

Курс составил профессор русского языка с 30-летним опытом, эксперт по фонетике, в Пекинском университете иностранных языков ЧжанЦзиньлань. В курсе 20 лекций, материал преподносится от букв до произношения. Курс подходит и для учащихся, имеющих базовые знания русского языка, которые хотят улучшить свое произношение.

2. Прорыв в русско-английском переводе для тестов по русскому языку 8-го уровня[6].

Автор курса - ЧжанЦзюньсян, доцент кафедры русского языка в Нанкинском университете и доктор философии по журналистике в МГУ.

Курс подготавливает учащихся к прохождению тестов по русскому языку. Анализирует трудности в русскокитайском переводе.

3. Русский язык 1 ЛюМяо[7].

Видеокурс содержит большое количество уроков для китайских учащихся.

4. Дорога в Россию[8].

Видеокурс предназначен для студентов продолжающего уровня.

5. Быстрый старт на русском языке - Университет Ванмен[9].

Автор курса - У Шилей, магистрант кафедры русского языка и литературы Пекинского университета, окончил русский факультет китайского университета Жэньминь.

Курс содержит 96 видеоуроков. Позволяет овладеть базовым словарным запасом и грамматикой для уровня повседневного общения. Курс рассказывает о национальных, культурных и литературных особенностях русского языка.

6. “Ура” Русский язык АБВ [10].

Видеокурс содержит 18 уроков. Освещает такие темы, как введение в русскую фонетику, элементарную грамматику, базовые навыки письма для начинающих учеников, закладывая прочную основу для перехода к углубленному русскому устному и письменному обучению в будущем.

7. Русская грамматика - Пекинский университет аэронавтики и космонавтики [11].

Видеокурс содержит лексическую и синтаксическую части, разбирает систему грамматики русского языка, представляя ее в наглядной форме таблиц. Анализируются трудности учащихся в понимании, овладении и использовании русского языка.

К курсу прилагаются упражнения разных уровней сложности.

8. Учите русский язык со мной - Университет Чжэцзян[12]. 
Курс для изучающих базовый русский язык. Вводный класс учит русскому произношению, паттернам и письму. Основная часть курса систематически преподает грамматику, тексты, диалоги и связанные с ними культурные знания русского языка.

Результаты. Если учесть вышеизложенное с учетом сложностей, актуализированной задачей теперь является создание качественного и эффективного видеоурока для обучения китайских студентов русскому языку как иностранному, включая разработку лингвометодических основ внедрения видеоурока.

То, что целевой аудиторией будут являться китайские студенты, задает определенный подход к формированию обучающего материала. Следует учесть лексические, фонетические, орфоэпические, морфологические особенности преподавания русского языка для учащихся с родным китайским языком. То, что подойдет для обучения, например, носителей европейских языков, уже недостаточно эффективно для носителей китайского. Наличие диалектов в китайском языке также вносит необходимость внесения этой особенности в видеокурсы.

Еще одним фактором являются консервативные образовательные традиции в Китае. Для повышения эффективности преподавания русского языка в контексте русской языковой личности имеет смысл вносить в образовательный процесс методы, снижающие интроверсию студентов и облегчающие психологическую нагрузку обучения новому языку. Видеокурсы позволят китайским учащимся дистанцироваться от учителя, иметь больше времени на усвоение материала, возможность в любой момент посмотреть видеоматериал заново и выполнить необходимые упражнения, не боясь ошибиться с ответами.

Для повышения вовлеченности видеоуроков могут применять систему комментариев под видеоуроками, а учитель в видео будет задавать вопросы, приглашая учащихся на них ответить в комментариях.

Заключение. Перечисленные в статье существующие видеоуроки недостаточно решают описанные проблемы, соответственно, разработка нового видеоурока обучения русскому языку как иностранному для китайских учащихся имеет новизну и актуальность.

\section{Список использованной литературы:}

1 Арестова О.Н., Бабанин Л.Н., Войскунский А.Е. Мотиваичия пользователей Интернета // Гуманитарные исследования в Интернете / Под редакиией А.Е. Войскунского. - М., 2000. С.75 - Сборник научных трудов.

2 Азимов Э.Г. Аудио-, видео-, компьютерные материаль в обучении иностранным языкам // Русский язык за рубежом. М., 2010. - №3. - С. 27-44. - журнал.

3 Арутюнов А.Р. Теория и практика создания учебника русского языка для иностранщев. М., 1990. - 245 с. книга.

4 Швачкин Н. К. Развитие фонематического восприятия речи в раннем детстве // Известия АПН РСФСР. Bыn. 13. 1948. С. 101-133. - журнал.

5 Чжан Цзиньлань. Быстрый старт русского с нуля//Пекинский университет иностранных языков [Электрон.ресурс]. - 2020. - URL: https://www.beiwaiclass.com/products/detail-1426.html(дата обращения: 08.02.2020).интернет источники

6 Чжсан Цзюньсян. Прорыв в русско-английском переводе для тестов по русскому языку 8-го уровня // Пекинский университет иностранных языков [Электрон.ресурс]. - 2020.2 - URL: https://www.beiwaiclass.com/products/detail-683.html(дата обращения: 05.03.2020). -интернет источники

7 Лю Мяо. Русский язык 1 // Пекинский университет иностранных языков [Электрон.ресурс]. - 2019. URL:https://youtube.com/playlist?list=PLycXmlzOfI4KVV2fMLsHU7BkqYLT8vZ3 (дата обращчения: 16.10.2019). интернет источники

8 Чжан Цзянтао. Дорога в Россию 2 // Тяньчжииун Интернет Школа [Электрон.ресурс. - 2019. URL:https://www.youtube.com/playlist?list=PLycXmlzOfI4LRxfwamp10pECXyj86vJuf (дата обращения: 12.12.2019). интернет источники

9 У Шилей. Быстрый старт на русском языке // Университет Ванмен [Электрон.ресурс]. - 2015. URL:https://www.wanmen.org/courses/586d23485f07127674135d2a/lectures/586d23535f071276741592ef

(даma обращения: 25.06.2015). -интернет источники

10 “Ура" Русский язык АБВ // Сианьский университет иностранных языков [Электрон.ресурс]. - 2019. - URL: http://moocs.unipus.cn/my/course/459/summary (дата обращения: 07.05.2019). -интернет источники

11 У Сяося. Русская грамматика//Пекинский университет аэронавтики и космонавтики [Электрон.ресурс]. 2019. - URL: https://www.icourse163.org/course/BUAA-1206676813?tid=1207012220(дата обращения: 25.11.2019). интернет источники

12 Ван Юн, Сюэ Ранран, Юань Мяосю. Учите русский язык со мной//Университет Чжсэизян [Электрон.ресурс]. - 2020. - URL: http://www.icourse163.org/course/ZJU-1206461833 (дата обращения: 24.02.2020). интернет источники

13 Быкова О.П. Телеуроки по русскому языку в обучении иностранных студентов-нефилологов // Современные технические средства в обучении русскому языку как иностранному: Сб. статей / под ред. В.Г. Логиновой, Н.И. Саиуйловой. М.,2009. - С. 30-47. - журнал.

14 Сысоев В.П., Евстигнеев М. Н. Разработка авторских учебных Интернет ресурсов по иностранному языку // Иностранные языки в школе.2008. - С. 8-16. - журнал.

15 Гончар И.А. Речевые ситуации как основа сюжетного видеофильма (коррекция и развитие навыков устного общения на начальном этапе обучения иностранцев русскому языку). СПб., 2006. - 204 с. - книга. 


\title{
References:
}

1. Arestova O.N., Babanin L.N., Voiskunski A.E. Motivasia pölzovatelei İnterneta // Gumanitarnye issledovania v İnternete / Pod redaksiei A.E. Voiskunskogo. - M., 2000. S.75 - Sbornik nauchnyh trudov.

2. Azimov E.G. Audio-, video-, kömpüternye materialy v obuchenii inostrannym iazykam // Ruski iazyk za rubejom. M., 2010. - №3. - S. 27-44. - jurnal.

3. Arutünov A.R. Teoria i praktika sozdania uchebnika ruskogo iazyka dlä inostransev. M., 1990. - 245 s. - kniga.

4. Şvachkin N. K. Razvitie fonematicheskogo vospriatia rechi v rannem detstve // İzvestia APN RSFSR. Vyp. 13. 1948. S. 101-133. - jurnal.

5. Chjan Szinlän. Bystryi start ruskogo s nulä//Pekinski universitet inostrannyh iazykov [Elektron.resurs]. - 2020. URL: https://www.beiwaiclass.com/products/detail-1426.html(data obraşenia: 08.02.2020).-internet istochniki

6. Chjan Szünsän. Proryv v rusko-angliskom perevode dlä testov po ruskomu iazyku 8-go urovnä // Pekinski universitet inostrannyh iazykov [Elektron.resurs]. - 2020. - URL: https://www.beiwaiclass.com/products/detail683.html(data obraşenia: 05.03.2020). -internet istochniki

7. Lü Mäo. Ruski iazyk $1 / /$ Pekinski universitet inostrannyh iazykov [Elektron.resurs]. - 2019. URL:https://youtube.com/playlist?list=PLycXmlzOfI4KVV2fMLsHU7BkqYLT8vZ3 (data obraşenia: 16.10.2019). -internet istochniki

8. Chjan Szäntao. Doroga v Rosiu 2 // Tänchjisun İnternet Şkola [Elektron.resurs. - 2019. URL:https://www.youtube.com/playlist?list=PLycXmlzOfI4LRxfwamp10pECXyj86vJuf (data obraşenia: 12.12.2019). -internet istochniki

9. U Şilei. Bystryi start na ruskom iazyke // Universitet Vanmen [Elektron.resurs]. - 2015. URL:https://www.wanmen.org/courses/586d23485f07127674135d2a/lectures/586d23535f071276741592ef (data obraşenia: 25.06.2015). -internet istochniki

10. "Ura" Ruski iazyk ABV // Siänski universitet inostrannyh iazykov [Elektron.resurs]. - 2019. - URL: http://moocs.unipus.cn/my/course/459/summary (data obraşenia: 07.05.2019). -internet istochniki

11. U Säosä. Ruskaia gramatika//Pekinski universitet aeronavtiki i kosmonavtiki [Elektron.resurs]. - 2019. - URL: https://www.icourse163.org/course/BUAA-1206676813?tid=1207012220(data obraşenia: 25.11.2019). -internet istochniki

12. Van İun, Süe Ranran, İuän Mäosü. Uchite ruski iazyk so mnoi//Universitet Chjeszän [Elektron.resurs]. - 2020. URL: http://www.icourse163.org/course/ZJU-1206461833 (data obraşenia: 24.02.2020). -internet istochniki

13. Bykova O.P. Teleuroki po ruskomu iazyku v obuchenii inostrannyh studentov-nefilologov // Sovremennye tehnicheskie sredstva v obuchenii ruskomu iazyku kak inostrannomu: Sb. statei / pod red. V.G. Loginovoi, N.İ. Saiuilovoi. M.,2009. - S. 30-47. - jurnal.

14. Sysoev V.P., Evstigneev M. N. Razrabotka avtorskih uchebnyh İnternet resursov po inostrannomu iazyku // İnostrannye iazyki v şkole.2008. - S. 8-16. - jurnal.

15. Gonchar İ.A. Rechevye situasii kak osnova süjetnogo videofilma (koreksia i razvitie navykov ustnogo obşenia na nachälnom etape obuchenia inostransev ruskomu iazyku). SPb., 2006. - 204 s. - kniga.

МРНТИ 378.016 $\quad$ https://doi.org/10.51889/2020-4.1728-7804.87

\author{
Matay S., ${ }^{1}$ Alikhan G. $^{2}$ \\ ${ }^{1,2}$ Al-Farabi kazakh national university, \\ Almaty, Kazakhstan
}

\section{EXPLORING A FEW PROBLEMS ENCOUNTERED BY KAZAKH STUDENTS IN LEARNING CHINESE SPECIAL QUESTIONS}

In view of the unsolved problems arising in the process of learning the Chinese language in Kazakhstan, especially the most important part of studying the structure of sentences in the language, that is, the most difficult part for students who are familiar with Chinese grammar. After several years of teaching experience, students seem to have mastered the special interrogative sentences and written and oral use that often appear in life. To further increase the effectiveness of teaching in the future educational process and reduce the number of unnecessary mistakes in the sentence and the process of speech, students decided to conduct research and control their daily work. It was analyzed that the mistakes are often done by students when doing exercises and explain the reasons.

Keywords: chinese, kazakh language; special interrogative sentences; interrogative words; analysis of biase 